\title{
PERCEPÇÃO AMBIENTAL DOS MORADORES DO ASSENTAMENTO VILA RURAL I DO MUNICÍPIO DE ALTA FLORESTA-MT
}

\begin{abstract}
Daiane Maria HAUBRICHT ${ }^{1}$
Franciele Aparecida FIORINI ${ }^{2}$

${ }^{1}$ Mestranda do Programa de Pós-graduação stricto sensu em Biodiversidade e Ecossistema Amazônicos da Universidade do Estado de Mato Grosso - UNEMAT. e-mail: daianehaubricht@yahoo.com.br

${ }^{2}$ Bióloga. e-mail: fran_fiorini95@hotmail.com.

Recebido em: 16/05/2014 - Aprovado em: 30/06/2014 - Disponibilizado em: 30/07/2014

Resumo: A reflexão sobre percepção ambiental é uma ferramenta para a educação ambiental e para as políticas públicas relacionadas ao meio ambiente. Através da percepção ambiental são estabelecidas as relações de afetividade do indivíduo para com o ambiente, possibilitando identificar as formas precisas em que essa educação possa sensibilizar e trabalhar as dificuldades ou dúvidas que os envolvidos possam vir a ter em relação às questões ambientais. Este trabalho objetivou investigar a percepção ambiental dos moradores da Vila Rural I em Alta Floresta- MT. A coleta e análise foram realizadas com base nos trabalhos desenvolvidos pelo Núcleo de Estudos em Percepção Ambiental (NEPAFaculdade Brasileira/UNIVIXVitória/ES) e também por pesquisa desenvolvida por Brambilla (2007). Percebeu-se que os entrevistados possuem laços afetivos que acarretam modificações em valores ambientais, porém demonstra necessidade de continuidade da pesquisa, abordando outras temáticas ambientais de modo a consolidar uma imagem completa do perfil do conhecimento ambiental e, por consequência, traçar planos de intervenção.
\end{abstract}

Palavras-chave: Percepção ambiental. Afetividade. Valores ambientais. Educação ambiental. Sensibilização.

\section{ENVIRONMENTAL PERCEPTIONS OF RESIDENTS OF SETTLEMENT RURAL VILLAGE I THE CITY OF ALTA FLORESTA -MT}

\begin{abstract}
The reflection on environmental perception is a tool for environmental education and for public policies related to the environment. Through environmental perception are established relationships of affectivity of the individual to with the environment, enabling to identify the precise ways in which this education can sensitize and work difficulties or doubts that may have those involved in environmental issues. This study aimed to investigate the environmental perception of the residents of the Village Rural I in Alta Floresta-MT. The collection and analysis were realized based on the work developed by the Nucleus for Research on Environmental Perception (NEPA-Brazilian School / UNIVIXVitória / ES) and also by research conducted by Brambilla (2007). It was noticed that the interviewees have emotional ties that entails changes in environmental values, but demonstrates the necessity for continuing research, addressing other environmental thematic in order to consolidate a complete picture of the profile of environmental knowledge and, consequently, develop intervention plans.
\end{abstract}

Keywords: Environmental perception. Affectivity. Environmental values. Environmental education. Awareness. 


\section{Introdução}

O meio ambiente vem sendo a grande preocupação da população mundial seja pelas mudanças provocadas pela ação do homem na natureza ou pela resposta que a natureza dá a essas ações. A relação do homem com o ambiente é uma preocupação pertinente ao quadro ambiental e social na atualidade, entretanto existem interesses e também conceitos distintos para o estabelecimento de parâmetros mediadores de tais relações (Oliveira \& Corona, 2008).

Para Amorim-Filho (2005) pode-se analisar o comportamento humano segundo suas aspirações, decisões e ações individuais e coletivas frente ao ambiente considerando-se suas atitudes, preferências, valores, percepções e imagens que a mente humana tem a capacidade de elaborar. Dessa forma, conforme Palma (2005) para que se possa compreender as inter-relações entre o homem e o ambiente, suas expectativas, satisfações e insatisfações, julgamentos e condutas, o estudo da percepção ambiental é de fundamental importância.

A percepção ambiental é definida por Faggionato (2009) como uma tomada de consciência do ambiente pelo homem, ou seja, o ato de perceber o ambiente que se está inserido, aprendendo a proteger e a cuidar do mesmo. O tema "Percepção Ambiental" vem atender a necessidade que se notou, de antes de serem propostas ações de Educação Ambiental, direcionar as atividades que deverão compor um programa de Educação
Ambiental, para temas que se tem curiosidade, interesse e, portanto, a sociedade está disposta a aprender.

Não basta ser sensível e estar engajado em movimentos de educação ambiental é necessário conhecer a percepção ambiental daqueles com os quais trabalha, pois, de acordo com Lopes et al. (2007) a percepção ambiental possibilita atuar junto a comunidade, proporcionando a oportunidade de fortalecer o contato com a questão ambiental, participando desde a construção e transmissão do conhecimento ecológico até a elaboração de opiniões pessoais sobre temas discutidos, para a realização de projetos ambientais que visam a melhoria da qualidade de vida desta comunidade. "Os resultados das pesquisas de percepção ambiental deverão fornecer subsídios para a elaboração de um projeto de Educação Ambiental de uma região" (Boing, 2006).

Soares (2005) descreve que o estudo da percepção ambiental integra elementos da psicologia, geografia, biologia e antropologia, entre outras ciências, a principal finalidade é compreender os distintos comportamentos do ser humano em relação ao meio ambiente. As percepções revelam o modo como se vive e se planeja o espaço, é resposta das diferentes interações entre ser humano e meio ambiente. A necessidade de levantamento da percepção ambiental é importante para identificar qual representação social que cada parcela da sociedade tem do meio ambiente, portanto este trabalho tem como objetivo investigar a 
percepção ambiental dos moradores do assentamento Vila Rural I do município de Alta Floresta quanto à questão ambiental.

\section{Material e Métodos}

2.1. Área de estudo: O estudo foi realizado no assentamento Vila Rural I, localizado no município de Alta Floresta - MT nas coordenadas geográficas $-35^{\circ} 00^{\prime} \mathrm{W}$ e $-9^{\circ}$ 15' S (Ramos et al. 2009).

\subsection{Metodologia: A definição da} metodologia foi baseada nos trabalhos do professor Roosevelt S. Fernandes, coordenador do Núcleo de Estudo em Percepção Ambiental - NEPA, da Faculdade Brasileira/UNIVIX - Vitória/ES, e também por pesquisa desenvolvida por Brambilla (2007).

A metodologia utilizada foi um estudo de caso dentro de uma abordagem qualitativa. Os sujeitos de estudo foram moradores do assentamento Vila Rural I localizada no município de Alta Floresta- MT.

Para obtenção dos dados foi utilizada entrevista com questões fechadas e abertas e estruturadas com base na coleta e análise de dados desenvolvidos por Brambilla (2007) e também pelo Núcleo de Estudos em Percepção Ambiental (NEPA), frente à identificação da percepção acerca dos principais temas do conhecimento ambiental. As questões e análise foram adaptadas levando em consideração o tipo/nível do público da pesquisa e os objetivos estabelecidos para a mesma.
A metodologia qualitativa segundo Marconi \& Lakatos (2004) fornece análise mais detalhada sobre as investigações, hábitos, atitudes e tendências de comportamento, identificando-se com o estudo de caso, o qual se refere ao levantamento com mais profundidade de determinado caso ou grupo humano sob todos os aspectos. Apresentando a entrevista como método fundamental de coleta de dados para essa metodologia.

A entrevista contou com 15 perguntas distribuídas em questões de múltipla escolha, específicas e/ou com justificativa (Anexo 1). O estudo foi realizado entre os dias 05 e 26 de junho de 2012 com 50 (cinquenta) entrevistados. Após, as informações foram analisadas, digitadas, revisadas e inseridas em uma planilha, sendo que a amostra resultou em um percentual aproximado de $30 \%$ das propriedades existentes na Vila Rural no ano de 2012/1.

\section{Resultados e Discussão}

O conjunto da amostra apresentou-se com $58 \%$ do sexo feminino e $42 \%$ do sexo masculino. A faixa etária variou entre 29 e 63 anos, tendo a maioria entre 50 e 60 anos (70\%). Em relação ao tamanho, todas as propriedades possuem menos de cinco hectares (há), dimensões aproximadas de $60 \mathrm{~m}$ de largura por $220 \mathrm{~m}$ de comprimento. Todos entrevistados apresentaram-se como proprietários. 
O assentamento Vila Rural I, possui 176 lotes rurais. Foi criado em 2002 por meio do Projeto "Nossa Terra, Nossa Gente" para atender aos trabalhadores do município em áreas do próprio município, sendo o Instituto de Terras de Mato Grosso (Intermat) responsável por medir e parcelar as terras. Segundo o Instituto de Terras de Mato Grosso (2012) as áreas destinadas à criação de vilas rurais estão localizadas nos entorno dos centros urbanos e são adquiridas pelo Governo do Estado ou em parceria com os municípios contemplados. Os lotes de 1,2 a 2,5 hectares são destinados, preferencialmente, para homens e mulheres com mais de 45 anos, que depois de selecionados, cadastrados e registrados no Sistema de Informações de Projetos de Reforma Agrária (Sipra/Incra), tornam-se habilitados à concessão de créditos destinados à agricultura familiar e à reforma agrária.

Quanto à principal atividade desenvolvida nas propriedades, a pesquisa mostrou que $100 \%$ desenvolvem sistemas de agricultura familiar, e juntamente, segundo os próprios moradores para aumento de renda ou/ para não desperdiçar os produtos, $68 \%$ arriscam na produção comercial. Destaca-se o argumento de um morador feito durante a entrevista, o qual menciona que como a propriedade é pequena arrenda outras áreas para o plantio de mandioca, a qual é entregue em vários estabelecimentos comerciais da cidade.
Conforme Ramos et al. (2009) os moradores da Vila Rural comercializam as espécies cultivadas, com destaque para os seguintes produtos: mandioca, abóbora, banana, cana, cupuaçu, feijão, laranja e maracujá.

Quando questionados sobre o que é meio ambiente, $76 \%$ dos entrevistados responderam que é a interação das diferentes formas de vida existentes no planeta, incluindo os seres humanos, $16 \%$ acreditam que são os recursos naturais que os seres humanos dependem para viver, já $8 \%$ que são os animais e as plantas que devemos preservar.

Leão \& Silva (1999) acreditam que o homem é um dos elementos do Ambiente, formado de partes: o biológico, o racional, o emocional, que estão em permanente integração e inter-relação entre si e com os outros elementos da natureza, nos diferentes níveis de sua evolução. Esta influência mútua fez nascer o homem social, que ao incorporar todas estas dimensões alicerçam a história da construção humana em estreita e contínua harmonia. Assim, pode-se considerar que o homem é um dos elementos do meio ambiente, e como tal, tudo o que faz à natureza acaba determinando a qualidade de vida, e que, a falta de conhecimento do significado do que é ser elemento da natureza aliada à desinformação das leis da natureza e das relações com podem levar a grandes desequilíbrios ambientais. 
No município os principais problemas ambientais afrontados pelos moradores são poluição dos rios/córregos (96\%), queimadas (74\%) e desmatamentos (12\%), além disso, nove entrevistados (18\%) acrescentam que a falta de água é o grande problema. Essa percepção da ausência faz com que a água passe a ser considerado um recurso natural, essencial à existência e ao bem-estar do homem e também à manutenção dos ecossistemas. Quanto à solução, os principais responsáveis por resolver os problemas ambientais na opinião dos entrevistados somos todos nós $(84 \%)$, seguido do governo Federal (12\%).

Deste modo, lembra-se que a preservação sustentável do planeta não é viável se não atender a satisfação básica de todos os habitantes da Terra. Demanda o contentamento dos seres vivos em todos os domínios/esferas e cabe a cada um de nos fazermos a nossa parte, para que o mundo se encontre em inteira harmonia.

\footnotetext{
"Todos têm direito ao meio ambiente ecologicamente equilibrado, bem de uso comum do povo e essencial à sadia qualidade de vida, impondo-se ao Poder Público e à coletividade o dever de defendê-lo e preservá-lo para as presentes e futuras gerações" (BRASIL, Constituição da República Federativa do Brasil, 1988).
}

Quando questionados sobre estarem fazendo alguma coisa para cuidar do meio ambiente, percebe-se que os entrevistados demonstram interesse e vontade de contribuir para sua proteção e qualidade, já que $68 \%$ dos entrevistados afirmam praticar alguma ação para cuidar do meio ambiente, mesmo sendo difícil convencer outras pessoas e $32 \%$ praticam alguma ação independente de outras pessoas.

Em relação como à natureza deveria ser $74 \%$ acreditam que está totalmente preservada, mas oferecendo as pessoas que dela dependem outras formas de trabalho que não a da exploração da natureza, e $26 \%$ acham que parcialmente preservada, pois as pessoas de que dela dependem precisam utilizar os recursos naturais disponíveis.

"Entendemos por preservar a
ação de proteger, contra a
destruição e qualquer forma de
dano ou degradação, um
ecossistema, uma área
geográfica ou espécies e
vegetais ameaçadas de
extinção, adotando se as
medidas preventivas
legalmente necessárias e as
medidas de vigilância
adequadas" (BRASIL, 1998).

Segundo os Parâmetros Curriculares Nacionais (BRASIL, 1998) interagindo com os elementos do seu ambiente, a humanidade provoca tipos de modificação que se transformam com o passar da história. E, ao transformar o ambiente, os seres humanos 
também mudam sua, própria visão a respeito da natureza e do meio em que vive.

Dos moradores entrevistados, $46 \%$ consideram que as pessoas do local onde moram, às vezes, se preocupam com os problemas ambientais, 38\% afirmam que o tempo todo, enquanto que $16 \%$ mencionam somente que sim, sem relacionar prosseguimento. Já em relação ao meio familiar, ou seja, em casa, $38 \%$ asseguram que sempre assuntos ligados ao meio ambiente são comentados, $28 \%$ que quase sempre, $24 \%$ responderam que poucas vezes e $10 \%$ relatam que nunca são mencionados esses assuntos em casa.

Esse resultado pode ser um indício de que baseado na experiência os moradores trazem informações e aprendem em casa, possuindo de tal modo conhecimentos e opiniões sobre o meio ambiente. Gonçalves et al. (2006) cita que a questão ambiental perante a sociedade vem tomando uma enorme amplitude dentre os assuntos mais abordados tanto em meios de comunicação como no âmbito escolar e familiar. Afirmando que a importância do levantamento deste assunto é imensurável tendo em vista que praticamente todo espaço já sofreu ou está sofrendo interferências do homem ou mesmo do ambiente.

A pesquisa, também procurou saber se a propriedade possuía Reserva Legal e Área de Preservação Ambiental, e qual o critério utilizado para a localização da Reserva. Constatou-se no decorrer da pesquisa a campo e depois verificada em contextos bibliográficos que em função do planejamento e da pequena quantidade de área de cada unidade, as mesmas apresentam reserva legal ou áreas protegidas em condomínio. Contudo para não fugir do objetivo estabelecido, a entrevista considerou a Reserva Legal como a área destinada pela Intermat como reserva. Assim, 38\% dos entrevistados declararam possuir Reserva Legal, e com exceção de 14\% em que a reserva se encontra ao entorno de rios/córregos, os demais afirmam que o critério utilizado foi proposto pela Intermat, que exigia dos proprietários aproximadamente quarenta metros (preferência à frente) destinados à reserva da propriedade. Ao mesmo tempo, foi possível diagnosticar que $52,63 \%$ do total das propriedades com reservas possuem estas através de plantios, e segundo esses moradores o cupuaçu, é a espécie mais utilizada na recuperação dessas áreas, e apenas 10,53\%, sem referirem-se as de entorno de rios/córregos que correspondem a $36,84 \%$, possuem reservas nativas, como mostra tabela 1 .

Tabela 1- Relação entre reservas nativas e reservas por plantios nas propriedades avaliadas na Vila Rural I em Alta Floresta - MT.

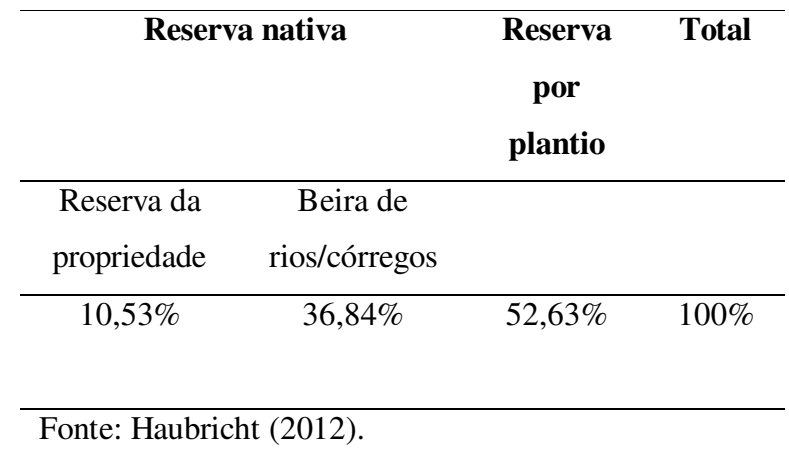


Os números mostram que a maioria dos moradores não seguiram as requisições estabelecidas pelo Projeto em relação à reserva, fato que pode ter raízes em culturas passadas, como observado no discurso de um morador que conta que seus antepassados consideravam o proprietário que não desmatasse toda sua área como preguiçoso. Entretanto, é importante ressaltar que alguns moradores já possuíram a reserva, a qual com o passar dos anos foi sendo destruída naturalmente.

De acordo com Filho (2005), o indivíduo ou grupo enxerga, interpreta e age em relação ao meio ambiente de acordo com interesses, necessidades e desejos, recebendo influências, sobretudo dos conhecimentos anteriormente adquiridos, dos valores, das normas grupais, enfim, de um conjunto de elementos que compõe sua herança cultural.

Com relação a itens propostos na entrevista e com os quais se identificam $87 \%$ dos entrevistados consideram-se parte integrante da natureza e responsável por ela, $76 \%$ respeitam as diversidades da natureza, $74 \%$ analisam criticamente os fenômenos naturais em favor da qualidade de vida e $2 \%$ compreendem os problemas ambientais de modo local. Para Lacreu (1998) a tomada de posição diante dos diferentes problemas do ambiente e as diferentes alternativas de solução tem necessariamente um aspecto ideológico. Quanto maior a informação que tenhamos a respeito, mais responsáveis serão as nossas opiniões e ações decorrentes das mesmas.

\section{Conclusão}

Diante dos resultados observa-se que essa pesquisa pode ser ampliada e continuada com outras investigações, em outra situação oportuna, isso porque o processo da Educação Ambiental é contínuo com transformações e construção de consensos, onde é possível perceber que são muito diversas as visões de mundo e os objetivos de ação para as problemáticas ambientais. E, percebendo através da pesquisa, que os entrevistados possuem laços afetivos que acarretam modificações positivas em valores ambientais, fica evidente a necessidade da sequência desse trabalho, abordando outros temas da temática ambiental de modo a consolidar uma imagem completa do perfil do conhecimento ambiental dos moradores e, por consequência, traçar planos mais amplos de intervenção. 


\section{REFERÊNCIAS BIBLIOGRÁFICAS}

AMORIM FILHO, O. B. Os Estudos da

Percepção como última Fronteira da

Gestão Ambiental - Disponível em: http://www.sites.uol.br/ivairr/percepcaoambi. htm. Acesso em 23 de junho de 2012.

BOING, L. A percepção ambiental como subsídio para a educação ambiental: estudo de caso do caminho do Itupava Paraná. Disponível em: http://www.physis.org.br/ecouc/Artigos/Artig o3.pdf. Acessado em: 23 de junho de 2012.

BRASIL. MEC. Parâmetros Curriculares Nacionais. Meio Ambiente. Brasília: SEF. 1998.

BRASIL. Constituição (1988). Constituição da República Federativa do Brasil. Brasília, DF, Senado, 1998.

FAgGiOnato, S. Percepção Ambiental. Disponível em: http://www.cdcc.sc.usp.br/bio/mat_percepcao amb.htm. Acessado em junho de 2012.

FILHO, T. A. G. Percepção ambiental. Disponível em: http://www.diariopopular.com.br/20_09_05/a rtigo.html. Acessado em: 20 de junho de 2012.

GONÇALVES, E. C; CRISTAL， L. B; CARVALHO, W. L. P. Estudos ambientais do Rio São José dos Dourados associados a Geotecnologias no ensino médio. Disponível em:

http://marte.dpi.inpe.br/col/dpi.inpe.br/sbsr@

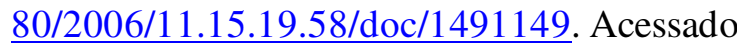
em: junho de 2012.

INTERMAT. Instituto de Terras de Mato

Grosso. Disponível em: http://www.intermat.mt.gov.br/. Acessado em: junho de 2012.

LACREU, L. I. Ecologia, ecologismo e abordagem ecológica no ensino das ciências naturais: variações sobre um tema: In: Didática das ciências naturais; contribuição e reflexões. Porto Alegre: ArtMed .1998.

LEÃO, A. L. C.; SILVA, L. M. A. Fazendo educação ambiental. Revista Atual. 4 ed. Recife. 1999. 32p.

LOPES, C. U. C. H.; MIRANDA, F. B. O.; BOTINHA, F. S. et al. A. Percepção Ambiental da comunidade imediata ao entorno do parque Felisberto Neves, BetimMG. SINAPSE AMBIENTAL. n.2, v.4. Dezembro 2007.

MARCONI, M. A.; LAKATOS, E. M. Metodologia Científica. 4 ed. São Paulo: Atlas. 2004. 
OLIVEIRA, K. A.; CORONA, H. M. P. A Percepção Ambiental como ferramenta de propostas educativas e de políticas Ambientais. ANAP BRASIL. Revista

Científica. Ano I. n.01. Junho 2008.

PALMA, I. R. Análise de percepção ambiental como instrumento ao planejamento da Educação Ambiental. Tese de Mestrado. Porto Alegre. 2005.

RAMOS, F. D. P.; ALMEIDA, E. V.; TAVARES, L. S.;. QUEIROZ, F. L. C, ROCHA, J. R. M.; FILHO, A. A. T. Análise socioeconômica e ambiental de sistemas agro florestais no Assentamento Vila Rural de Alta Floresta, Mato Grosso. I BIOTA - Ciclo de Estudos de Biologia de Tangará da Serra. Resumo expandido. 2009.

SOARES, S. M. V. A percepção ambiental da população noronhense em relação à área de preservação ambiental. Recife, 2005. Pós-Graduação em Gestão e Política Ambiental do Departamento de Letras e Ciências Humanas. Campus universitário de Recife- Universidade Federal Rural de Pernambuco, 96p. 